\title{
The Failure of the Radical Left Project in Italy: The Case of the Refoundation Communist Party (PRC)
}

\author{
Fabio de Nardis \\ Center of Studies on Politics and Society \\ Department of Social Sciences and Communication \\ University of Salento \\ Via dei Salesiani 2, 73100 Lecce (Italy) \\ Tel: 39-339-362-2420_E-mail: fabio.denardis@unisalento.it
}

Received: June 1, $2011 \quad$ Accepted: June 29, $2011 \quad$ doi:10.5539/jpl.v4n2p36

\begin{abstract}
In Italy during the last years It's been possible to observe the structuring and then the partial de-structuring of a close bond between the movement for a global justice (and other local movements) and the Refoundation Communist Party (Prc). Since 1999, Prc started to debate some principles of classic Leninism through a critic re-reading of the communist experiences of the $\mathrm{XX}$ century and the consequent consciousness of the communist no-self-sufficiency. After this, the leaders of the party could throw out the new strategy of an horizontal link to social movements. The relationship between Prc and social movements seem to go on without particular problems until the participation of Prc to the center-left govern in a moderate coalition. This paper intend to analyse the dynamics of this relationship by using, on one hand, the data from a survey carried out during the last four European Social Forum regarding the attitude of Italian movement activists on their relationship with traditional political institutions; on the other hand, we will analyse the interior debate of the Refoundation Communist Party by using documents published in occasion of the $7^{\text {th }}$ National Congress with particular regard to the articles published on the party's newspaper "Liberazione" for the tribune of the Congress. All the documents will be analysed with a specific computer program for content analysis.
\end{abstract}

Keywords: Social Movements, Political Parties, Refoundation Communist Party, left, Political Culture

\section{The failure of an alternative project}

As a consequence of the 2008 elections, held on April $13^{\text {th }}$ and $14^{\text {th }}$, the communists have been ejected from the Italian parliament. This forces the left wing to reassess its strategy in a hostile political environment, within the logic of a compulsory bipolar party system that leaves little room to the not aligned forces, aided by an electoral system that is willing to reward centripetal collective movements. The Italian political organization of the left wing called "Sinistra Arcobaleno", born as an attempt to unify the political forces of the democratic Italian party, suffers an electoral defeat. The PRC that had bet on the unitary hypothesis is pushed into a discussion about the policy unit and about redefining its party leadership team. The Governing experience has strongly weakened the privileged relationship between the party and the movements, confirming the ever lasting difficult relationship that they have when they take part in politics in spite of the fact that the PRC has invested a lot in this relationship with the movement, over the years, about a different globalization (de Nardis 2006; della Porta 1996; 2001; 2007; della Porta, Diani 2006; Rucht 1990; Norris 2002; Kitschelt 2003). As a matter of fact, in a previous research made about the first European social forum, it was observed that many activists of the movement for the global justice, had been active in participating to the PRC political party and intended to continue to do so in the future. This course of action is generally confirmed by the subsequent forums (de Nardis 2003; 2004a, 2004b). Nevertheless, in several researches made about the Italian left wing an overlapping between the activism movements and the party was found.

In specific, in a survey about delegates, appeared that about 57\% of the interviewees, that enrolled in the PRC, during the VI Congress (in Venice, in 2005), thought that the party should officially speak about the social petitions called forth by the committees and the movements (Bordandini, Di Virgilio 2005; Andretta, della Porta, Mosca, Reiter 2002; della Porta, Andretta, Mosca 2003; della Porta, Andretta, Mosca, Reiter 2006). It is undoubted that the participation of the communists to the Prodi Govern has weakened their opposing vocation and this has also been confirmed in studies where it is clearly stated that a valuable tuning amongst the left wing parties is mainly possible 
when these parties are in opposition (della Porta, 2007). Still, the PRC has started a process of cultural and organizational transformation that has in part turned it away from the classic model of mass parties (Katz, Mair 1992; Mair 1992) projecting it towards a decentralized networking structure only suitable to the strategic objective of cohesion to the movement for a global justice. This way, the internal party conflicts are a consequence of its own organization that was not born as a monolithic block but as a collection of components coming from different political situations only partially referenced to the tradition of the Italian communist party (Pci) (Dormagen 1996; Bertolino 2004). But it is during the IV Congress (in March 1999) that the most radical phase of the political and cultural transformation is launched. After the Prodi governing experience, the PRC is shot forth in a phase of new political leading role and the internal differences are heightened by the creation of organized components. If before the configuration of a new opposing left wing was envisioned along with the need to rebuild the initial social and anti-capitalist block, without excluding an alliance strategy for the government, after the crisis of 1998 the reconstruction of that block was envisioned as a social horizon oriented towards unhinging the bipolar logic to which the Italian political system had come to. Within this view, a critical evaluation of the traditional organizational model is developed, suggesting the hypothesis to identity renewal that would become the new movements' challenge.

Hence, the "active member" looses his/her acknowledged centrality within all the communist parties in favor of a renewed attention towards the 'fellow travelers' and the enrolled members, who interpret the colossal obstacles to the participation as the crisis of the job market, time spent working and just living. Although, in the International arena the privileged relationship with the movement sets aside the organic relationship amongst the other communist parties, a prospective that gives power to the growth of the anti-globalization mobilizations. In fact, in the 63 thesis presented by the secretary, in the occasion of the V Congress (in April 2002), the intention to move the strategic axis of the party within a proper political and institutional sphere is reinforced. It is so considered concluded a chapter of the history of the classic labor movement, directing one's attention on the anti-globalization movement as a revolutionary entity within the communist culture that contaminates itself through a critical environmental thought that is also feminist and pacifist. The Lenin imprinting is so abandoned and with it the theory of the upheaval of the system through the seizure of power. Thus, an organic relationship is suggested to the movements without any hegemonic demand. The PRC doesn't take part to the social movements but it becomes part of them. So, in the VI Congress (March 2005), the path to "realigning aims" is completed, founded on the cornerstone of contamination and on the critical evaluation of power and nonviolence (de Nardis 2005; de Nardis 2009; de Nardis, della Ratta 2006). At the same time, the criticism to bipolarism and alliance strategy is put up for discussion accepting the possibility of a governmental agreement between the lines of the moderate left wing. In fact, this "splitting" is never pushed to the extent of a substitution of the ultimate aim of the organization i.e. overcoming the capitalist production way. This is because a majority coalition within a party may hardly cause forms that would create a "substitution of the aims" connected to the collective ideology (Michels 1998). Through them it is in fact possible to offer those collective (or symbolic) incentives that guarantee a base of loyalty coming from the activists. (Note 1)

In this paper, we will analyze the processes of elaboration of the defeat through the dynamics of the PRC VII Congress held in Chianciano-Italy, on July $24^{\text {th }}-27^{\text {th }}, 2008$, where for the first time after fourteen years we registered a change in the conformation of the dominant coalition. We will observe the processes that have broken down and recomposed the leadership groups through the contents analysis of five congressional documents, none of which has reached the absolute majority of the members' votes, requiring the establishment of a coalition amongst its different components. In the end, we will use the lexicon-textual analysis tools to analyze the content of the sustaining speeches of the different congressional documents published on the party newspaper called "Liberazione" from May $22^{\text {nd }}$ to July $15^{\text {th }}, 2008$, to a total of 76 articles divided amongst the five motions.

\section{The conformation of the dominant coalition}

In order to examine the organizational structure of a political party it is necessary to investigate its internal power structure. To understand how it is distributed within the organization, how it reproduces and how the power asymmetries are modified. It is undeniable that the leadership of every political party has a large controlling capacity. However exercising this capacity cannot be arbitrary. Blau (1964) talked about power as a trading relationship which manifests itself within an "unbalanced negotiation" where the last of the militants has some resource, even if it is simply the threat of leaving the organization. In this context it is possible to distinguish between horizontal negotiations (between leadership groups) and vertical ones (between leaders and its basis). The broader the freedom that the leadership groups are able to conquer in their vertical negotiations, the greater resources they will have available to engage in horizontal ones. That is why the chase to the membership vote becomes a fundamental aspect of the internal political party dialectics particularly when there is a congressional comparison. When one speaks of leadership within a political party, one never refers to just a man or a woman. The leader has to be subjected to the 
negotiation processes (horizontal ones) within the leadership group. This way, we have chosen to use the definition of "dominant coalition" to describe the leadership in its whole. Its features may be analyzed along two dimensions: the internal cohesion degree and the stability degree (Panebianco 1982, 87). The cohesion degree of a dominant coalition depends on the existence of fractions, intended as well organized groups, or tendencies, i.e. weakly organized groups (Rose 1976; Belloni, Beller 1978). The stability degree instead has to do with the horizontal exchange between élites in specific the level of the precarious role of the already compromised summit members. These two elements combined define the conformation of a dominant coalition that is different from its composition that identifies instead, the men and women that belong to it. The PRC has always been characterized by dominant coalitions within which different sensibilities and tendencies lived together and yet their framework has always been characterized by a certain margin of cohesion and stability mostly owed to the absence of fractions that at least from the VI Congress onward have been left out of the political party management (de Nardis 2005). The electoral defeat served as an external stimulus to determine a change of the organizational order that in this case corresponded to a change of conformation of the dominant coalition, restructuring both the vertical (élite-basis exchange) and the horizontal (élite-élite exchange) power games. Such a change may be broken up into three phases: the first one caused by an organizational crisis due to a strong environmental pressure, in this case the electoral defeat; the second phase lies in the replacement of the leadership group and the subsequent structure of the dominant coalition; the third phase consists in the organizational restructuring of the rules of the game, including the re-definition of the official organization aim. The definition of new summit alliances takes place in the first Political National Committee after the April $19^{\text {th }}-20^{\text {th }} 2008$ defeat, when the exiting leadership group becomes part of the minority also due to the convergence of the "bias" of the previous minister Paolo Ferrero and the recognition of the leading group of the "fraction" called "to be communists - Essere Comunisti" lead by Claudio Grassi, who in the VI Congress had been the minority motion leader. Hence, the dominant coalition breaks down, allowing the creation of an interim majority that leads the political party towards the VII Congress. The new summit convergence indicates the movements of the leading groups between the VI and the VII Congress.

Excluding the old motions 3 and 4, respectively lead by Ferrando and Malabarba, whose members had already given birth to two distinct splits, because they didn't share the idea of participating to the centre-left government, it is worth mentioning how the leaders of the dominant coalition of the VI Congress would parcel out in three clear-cut motions, during the VII Congress.

The first motion, whose primary subscriber was Maurizio Acerbo, is the product of the convergence between "social left wing" lead by Ferrero, the movement-oriented tendency lead by Mantovani that in Venice supported the line of Bertinotti, and by the "To be Communists - Essere Comunisti" component lead by Grassi. The second one, instead, coupled a good portion of the majority lead by the president of the Apulia region Nichi Vendola. The third motion resulted from the alliance between the old group lead by Grassi in the past Congress along with the magazine "L'Ernesto" that together had given birth to the previous second motion and to a multifaceted cartel that was born by the convergence of the one hundred territorial circles. The forth motion whose primary subscriber was Claudio Bellotti corresponds to the previous fifth document formed around the group that supported the magazine "Falce e Martello", that has always taken alternative positions compared to the majority of the party. While the fifth motion was supported by two prominent leaders: Walter De Cesaris and Franco Russo. None of these documents went over $50 \%$ of the consensus needed to give birth to a new dominant coalition. Neither the supporters of the first document, nor those who supported the second one, that hoped to re-conquer the majority, aiming to the popularity of Nichi Vendola, self powered by what Robert Tucker would have defined as "circumstantial charisma", i.e. not determined by anointing leading personality traits, but rather by a moment of acute social stress that predisposes people to look for a leader. As matters of fact, to quote Tucker, the members of the PRC were inclined to follow with enthusiastic loyalty and to perceive as extraordinarily qualified a leader that offered them a way out from the stressful situation (Tucker 1970, 81-82). The five motions are voted in the conventions of 2.081 affiliated circles for a grand total of 43.546 valid votes: a clear sign of the persistent vitality of the political party activist body. Motion n.1 obtains $40,3 \%$ of consensus (out of 17.556 possible votes), motion n. 2 secured $47,3 \%$ votes (out of 20.579 possible votes), motion n.3 gained 7,7\% votes (out of 3.349 possible votes), motion n.4 attained 3,2\% votes (out of 1.384 possible votes), while motion n. 5 reached $1,5 \%$ votes (out of 668 possible votes). Therefore, the distribution of votes renders the picture of a clearly divided political party so split to impede the making of a dominant coalition and ruling out the possibility of a horizontal negotiation that will not be able to get any vertical confirmation mainly due to the presence of at least three fractions within the party: Essere Comunisti; L'Ernesto and Falce e Martello. Thus, it is not by chance that in Chianciano we witnessed an agreement amongst the delegates of motion n.1, 3, 4 and 5 that allowed, with a very tight margin, the election of Paolo Ferrero, while the motion n. 2 leader declared to have given birth to a new political and cultural area, called Refoundation for the left wing that will bloom into the alternative cartel to the PRC called Left and Freedom, in proximity to the June 2009 European elections. 


\section{Comparing the motions}

We will now analyze the content of the five motions. We have decided to analytically divide its contents in three categories: political party, left wing and movements.

\subsection{The Political Party}

In the first document it is stated that the historical function of the Refoundation Communist Party is not used up asserting the need of launching once again the political party within a unitary project of social forces that while expressing different experiences and identities share the same criticism towards the right wing governmental neo-liberalism. Although, the process that brought to the birth of the "Sinistra Arcobaleno" cartel needs to be reversed. The "Sinistra Arcobaleno" has been criticized to be the result of a hasty agreement between political classes that weren't clear on certain strategic junctions. Similarly, those who now speak of a refoundation party "without any adjective to it" are criticized (by those who rummage through the allusion of the second document) as leaning towards a "weak thought" crushed by the rhetoric of a thought that goes "beyond and without any aim", precisely when it is necessary to oppose the "strong thought" of an antagonist political subjective judgment to the vortex of social contradiction in order to be able to "free society and nature from the constrain of capital enhancement". This doesn't have to lead to a fall back within the comforting boundaries of a closed identity, rather, it has to contribute to "make a thesis and to put into practice what it means to be a communist today". We are not talking about a static uniform but preferably "a search made through the belief that the current social system, along with its flaws and its violence, isn't the end of the story". This way of thinking forces an organizational strengthening of the political party that will allow its establishment within the social and local government boundaries. Along these behavioral lines, there is no lack of awareness on the limits of the political party mold that motivate to continue on the road of trial and error and on the road of innovation, organizing battles and disputes practicing ways of mutuality "within the space and time of our everyday life". Also, in the second document, it is stated that the Congress role is to "save the Refoundation Communist Party" starting from the fact that there is a fracture of the nostalgic demeanor between the political party and its people. Furthermore, it is recognized the fact that a simple "maintenance" of the organization structures will not be enough if it is not coupled with a careful consideration of the mistakes built up by an inability to put into practice a political party model and a model of internal life that is close to a "radical reform of the politics, to a non violent critical evaluation of the power and to a hierarchical relationship model". Therefore, it is not necessary to give up the opportunity to renew the political behavior to regain a "radical horizon of change and the ambition of a "real movement" in the relationship with the defeated people". This situation requires a self improving of the political party that will be possible only welcoming "the external stimuli to practical ways". The party model that it is aspired to in the second document is therefore that of an open minded political party, able to relate to its society "in the deepest meaning of the term" where it would be meaningful to create "collective, innovative and supportive experiences" at a local government level. Differently, the authors of the third document believe that the VII Congress objective has to be that of saving the Refoundation Communist Party as a activist heritage along with its experience and its ability of creating battles and movements. However, this will "only happen if the refoundation/reconstruction of a stronger communist party is re-launched on popular basis, within the frame of a broader process of unity of the anti-capitalist left wing”. This way, the PRC should deal with the issue of overcoming the communist Diaspora "re-aggregating the many lost forces, with a speech that focuses on content, collective social practices, self-governing criticism and a project that gives a clear alternative to the Democratic Party”. In order to do so, it is necessary to have a well organized political party that lives the internal dialectic as an opportunity. Also, in the forth document the need to save the PRC is expressed that "remains the main force of the left wing". But this it is only possible through the elaboration of the schematic and organizational political basis, able to give a meaning to the political activists, starting with abandoning any self-governing temptation, to reduce the gap between the leading group and the political party and to reduce the gap between the political party and the working force. Therefore, a great communist party is needed "freed of the incrustation of Stalinism" that "would present itself as a general organization of the working class and of all the exploited". Additionally, the authors of the fifth document also showed a "collective commitment to safeguard the PRC heritage and its culture, taking care of its existence" and making theirs "the horizon of a new mutuality" that has to become a way of behaving within politics. Recalling the notion of the "social political party" also present in the first and second document.

\subsection{The Left Wing}

In the first document, the suggestion of "overcoming" the Refoundation Communist Party within a left wing constituent, presented by preeminent party representatives as an irreversible perspective, is criticized. The electoral defeat reasons don't have to be tracked within the organizational forms of the political left wing but rather in the structural issue of a relationship between the left wing and the Italian society. A left wing constituent would 
represent the denial of the Refoundation Communist Party project based upon "the dialectic unity of two terms that mutually qualify: the choice of the radical innovation and the choice of critically retracing a qualified political strand taken from the revolution theme, intended as overcoming the capitalist production way". This doesn't contradict the basic reasons of the need for a strategic process to unify the left wing, motivated by the fact that, today, only a portion of those who carry out a left wing oriented social and political activity recognize themselves as part of a political party. Committees, movements, associations and unions, carry out, in fact, volunteering activities that are socially aggregating and may participate to a broader unifying process starting from the definition of a common political project. An idea of a left wing that is diametrically the opposite of that "left wing without a soul" represented by the electoral cartel that was defeated in the political elections. Although, in the second document, it is explicitly stated that “the existence of the Refoundation Communist Party isn't an available asset” and therefore its dissolution isn't up for discussion, emphasizing the fact that it has to have the courage of start up a social, political and movemental process of reconstruction "pursuing a broader mass dimension that will extend beyond the organizational boundaries" that will take place "within the constituent sphere of possibility of a new political discussion" that would take into account democracy as a condition of the reconstruction of an alternative and open minded left wing. This would symbolize building a new political entity "that is unitary on a political level, on one hand, and plural regarding cultures and experiences of which is made, on the other hand", and this because the new left wing "cannot come to life within old forms". Also, authors of the third document appear to be focused on the need of urging a re-aggregating process towards the left wing, but they perceive this as a subordinate issue to the priority of reconstructing the communist left wing Diaspora. This way, they suggest two reconstruction unitary and parallel processes: "the first one, between the forces that retrace communism and Marxism [...] while the second one, on the basis of battles and common contents, of an anti-capitalist left wing that offers an open minded alternative”. Moreover, in the forth document, any perspective of a constituent or of a federation of the left wing is criticized. That would represent two different ways, yet too similar, to potentially cause a "division in the right wing of the Refoundation Communist Party". "Unitary productive processes may be enabled in the presence of a re-launch of the mass mobilization and the central role of the lower class". At least, it is necessary to urge the strategic hypotheses of class unity along with the lively working force, as for example some clusters of the union left wing and of the base, with which the PRC has stopped to have a dialogue due to its stay within a moderate government. Furthermore, the writers of the fifth document believe that a "left wing constituent" could have been launched in 2003, i.e. during the phase of the greater qualitative and quantitative spreading of the large anti-globalist and pacifist mobilizations. Today, a similar process may translate into the umpteenth agreement amongst political classes. Nevertheless, to launch a unitary conversation within the left wing is the solution however "the organizational and political forms that the left wing may take aren't definable by the PRC”. A reference model may be the European left wing that represented a useful innovation along with an effort to aggregate the left side, which didn't foresee the dissolution of its participants, but that was instead configured as a "common ground legitimized by the recognition of the autonomy of the individual political forces".

\subsection{Social Movements}

In the first document the choice of a strategic cohesion to the movements is clearly declined. To countervail the right wing hegemony and to build an alternative society it is needed to rebuild the relationships with the right wing members that may also be employed in the relations with the various movements. Hence, this is the answer to the defeat: to participate actively to the alter-globalization movement activities. To recuperate an organic relationship with the movements will allow a "revitalization of the democratic and participation paths", rebuilding "the social leading role able to weave the social class matter with the strengthening of the social ties and the reconstruction of supportive territorial communities". Also, in the second document the choice of a strategic cohesion to the movements is claimed, because it is only through them and "in their totality [...] that one can give birth to the chance of victory". In this case, too, one goes back to the VI Congress when the process started and ripened at the end of the 90's and was later on revitalized by the participation to the mobilization in Genoa in 2001 and the subsequent explosion of the global movement. Thanks to the movements we have been able to connect the communist tradition and the working class movement with the cultural criticism delivered by the pacifist, feminist and environmentalist movements with which the Refoundation Communist Party has to continue to coexist without any hegemonic demand. This is one more reason to overcome the political Party forms of innovation. "Political entity and social entity have to be put back in relation". The third document, instead, suggests a change in the course of action: to practice an absolute cohesion as voiced by the party majority. A large anti-capitalist left wing is established, in fact, on the basis of a political platform and in the heat of a social battle that the communists have to always connect to the main conflict between assets and employment, however "to practice cohesion amongst the movements doesn't mean to give up the autonomy". In fact, communists have to be part of the battle movements helping to promoted them and also helping to organize them and this requires "a new method in relating to the 
movements". This is because "a communist is called to answer in first person to his/her needs" taking upon himself/herself the duty of "coordinating” the battles. The authors of the forth document don't spend much time on analyzing movements in general, however they deem pivotal the role of the communist party within the reorganization process especially in re-launching a big working force movement that would face the mainly regressive transformations of the social system and of the production, mobilizing itself on the crucial themes of nationalization and the means of production working force control. The fifth document is the one that strongly underlines the need to keep on the nonviolence route, and on the route of power criticism, also underlining the absolute need for cohesion within the movements, because only from them and from the mobilization against neo-liberalism "the division between morals and politics has been put up for discussion", succeeding to articulate a nexus between morale, politics and rights.

\section{The themes of the congressional tribune}

Let's proceed into the contents analysis of the articles in favor of one of the motions published on the Party newspaper, underlining political culture elements. First of all, it is necessary to identify the shared themes. In order to do that, we will select the "repeated segments", i.e. those excerpts that repeat themselves several times and in the same sequence creating typical sentences thus identifying some thematic categories that will be a useful tool in the future analytical phases. We will then strengthen the categories that surfaced while selecting key words and specific words. To do that, we will calculate a statistical relevance index that will allow us to evaluate the meaning of the text segments, using the $I S$ index, that runs on a text analysis computer program. (Note 2)

Selecting a set of repeated segments derived by the overall collection of writings, we have been able to obtain three thematic categories: the party and the left wing, economy and employment, social movements.

The category called the Party and the left wing is rich in documents that allow us to get into the heat of the discussion within the PRC. It deals with the <sinistra arcobaleno>, the electoral coalition that was defeated in the political elections and consequently <ejected from the Italian parliament> and also criticized today for being the result of <summit operations> and for being unable to convince the voters of its <social usefulness>. In the documents, the topic of <rifondazione comunista $>$ (communist refoundation), is discussed as a process and as an organization that needs to be salvaged. The idea of $<$ a new political entity $>$ is supported by the authors of the second document while the thought is criticized by all the others who dispute the hypothesis of <overcoming the PRC>. The need to work on $<$ social rooting $>$ is taken into account as the only antidote to the risk of a $<$ Party dissolution $>$ which needs to be re-launched, instead, not to lock it into the comforting shell of an <identity niche $>$ and neither to bend it to the project of a <unitary and plural entity>, highly supported in the second document. In the category it is also discussed the topic of a $<$ new refoundation $>$ able to define a $<$ strategic perspective $>$ that will also deal with the construction of a <real movement $>$ of the <anti-capitalist left wing $>$ and not merely a collection of $<$ political classes $>$ and <leading groups $>$, but rather a <communist refounded Party $>$ able to re-define its <reason to exist> within the shared house of the $<$ European left wing $>$. A Party that is able to promote, starting from itself and from the bottom, a strategic identity taking into account the different personalities of the <popular left wing $>$ while building, when possible, <left wing houses $>$ that not simply represent the clue for the founding of <other formations $>$ that retrace a <left wing without any adjectives $>$ where communism is reduced to one of many $<$ cultural tendencies $>$ (Note 3). Additionally, in the category of economy and employment, the following references stand out: the need to build a new < working class movement> able to mobilize the working class against the arrogance of the <capitalistic system> within the theoretical picture that would recognize the pivotal role of the $<$ contradiction between assets and employment $>$. This pertains to both $<$ Italian workers $>$ as well as <immigrant workers $>$ victims of the deregulation attempt of the <job market>. However, the current priority is to prevent the Italian Industrial Association (Confindustria) and the Italian central right wing government projects from affecting the guarantees offered by the <national employment contract>. Also, the social movements have a strong baring within the PRC and many references can be found about the need to salvage the <relationship amongst movements> along with the territorial self-management experiences like those voiced in the <social centers $>$ in the name of a $<$ shared democracy $>$ well known to the communist militants who participated to the experience of the <social forums $>$ starting from the first worldwide forum in $<$ Porto Alegre $>$ for $<$ an alternative world $>$ inspired on the need to tune in with the conflict experiences. Furthermore, the key words have been detected through a term relevance criterion that allows us to select significant graphic forms, i.e. overused forms when compared to the referential lexicon (POLIF) coming from a wide sample of contemporary language. (Note 4)

The category called the Party and the left wing is also rich in words like; <refoundation> intended as Party and mainly used by the supporters of the motion $n .1$ and 5 . Furthermore, the word <refoundation $>$ is meant as a process and mostly used in text that support motion n.3. Furthermore, on one hand, the references to the PRC are chiefly used by the alternative motions within the second document: <party>, <communist>, <comrades>, 
$<$ communism $>$ and $<$ identity $>$ while, on the other hand, the supporters of the first document talk about $<$ constituent $>$ and $<$ left wing $>$ in two very different ways. The topics of $<$ self criticism $>$, $<$ participation $>$ and $<$ transformation $>$ are also well distributed amongst the various motions along with words like: <leaders $>$ and $<$ leaderism $>$ which are instead supported by the patrons of the first and third motion who focus on the $<$ rooting $>$ issue.

In a different category, called economy and employment we found words such as $<$ blue-collar worker/s $>$ along with the word <precariousness>, mostly used by the supporters of the first and second motions. Also, words like $<$ workers $>$ and $<$ factories $>$ are mentioned in specific by the supporters of the forth motion as consistent with their political culture. The word <class> instead, is preponderantly mentioned by the supporters of motion 1, 3 and 4 . Within category number 4 also known as social movements we didn't find many recurrent graphical forms. We only indentified the words $<$ movement/s $>$ well distributed amongst the supporters of the five motions and the word $<$ committee> mostly mentioned by the supporters of the forth document. In the end, we would like to detect the basic specificity of the words. In order to do this, it is necessary to create a relation between the different graphical forms present in the text with those present in the other four documents. By comparing the participation in favor of the five documents, it is possible to select some words counting how many times they appear in a given text in favor of a motion rather than in other ones. To better explain, if a word such as <left wing> recurs 100 times in the whole collection of motions, however only 10 of these recur in the participation in favor of the first four motions and 90 of them are in favor of the fifth one, we will say that the word "left wing" has a high degree of basic specificity for the supporters of the fifth document. Thus, if a word is characterized by high degrees of positive specificity in favor of a motion, the very same word has to be intended as having a negative specificity for the remaining four motions. As we can see in table number 4 , those words that in the first motion reach high degrees of specificity are: <culture/s $>$ and $<$ document $>$ where the latter refers to the congressional document. Understandably, also the word <entity $>$ is present and we matched it with the word <unique> which echoes of the criticism mostly supported by the previous leadership group lead by <Bertinotti $>$, in favor of the <overcoming $>$ of the PRC and in favor of a new political entity of the left wing. Against this hypothesis, the idea of <independence $>$ of the Refoundation Communist Party opposed to that of $<$ constituents $>$ without giving up the need to reunite the $<$ left wings $>$ within a collective opposing project to the right wings and the government.

The specific words of the second document are referred to the <analysis $>$ of the context in which the $<$ left wing $>$ has to rebuild itself. Hence, words like $<$ employment $>$, $<$ crisis $>$ and $<$ defeat $>$ stand out, along with $<$ fear $>$ due to the loneliness of the contemporary citizen that the right wing politicizes attacking above all the <migrant $>$ population. Vis-à-vis such a difficult situation the PRC should enhance the effort of all the <members $>$ to the $<$ circles $>$ having the courage to <change $>$ its political $<$ practices $>$ within a $<$ reconstruction $>$ project of the $<$ left wing $>$ that will start from the elaboration of a new <imaginary>. However, not all the words that reach negative degrees of specificity in the participation in favor of the second document are necessarily references to the <Party $>$ and to the <communist> identity. On the contrary, in the third document words with a high degree of positive specificity are those that may be referred to a practical and identitarian dimension, so, words like $<$ communist party $>$, $<$ leaders $>$, $<$ clubs $>,<$ PRC $>$, $<$ communism $>$ stand out re-claiming the need to redefine a new $<$ course of actions $>$. This is the only possible way to reach to so hoped for $<$ communist $><$ unity $>$ not founded on summit operations but rather on a renewed ability to fuel the conflict and the $<$ class $>$ battles. Amongst the supporters of the forth document, words like <worker/s $>$, <blue-collar worker $>$, <class $>$, $<$ firm $>$, <factories $>$, <wage $>$, <welfare $>$, $<$ contract $>$, <owners $>$, <bourgeoisie $>$ stand out and they are referenced to contradiction between assets and employment along with other words that reference instead to the internal party political dimension like <center right wing $>,<$ Government $>$ and $<$ Prodi $>$ which denote the left wing need to restart from a critical evaluation of the previous government experience. Furthermore, in the participation in favor of the fifth document we noticed specific words connected to the congressional moment, such as: <congress $>,<$ Party $>$, <let's disarm $>$ which invite us to moderate the internal debate in the name of unity and reconstruction. Also, authors spoke about $<$ nonviolence $>$ and $<$ democracy $>$ two related concepts that are part of the most recent acquisitions of the Refoundation Communist Party. In the end, the word $<$ Genoa $>$ is also mentioned as to give importance to a certain movement dimension within an international picture that identifies itself with words like $<$ world $>$ and $<$ European $>$.

\section{Contents of the congressional tribune}

Now we will deepen the understanding of the topic at hand analyzing the concordances, i.e. the context in which certain words or segments of text are used, specifying the position of the authors on the axes of the four thematic categories identified: the party and the left wing, politics and society, economy and employment, social movements. (Note 5)

\subsection{The party and the left wing}

The theme of the "party" represents the pivotal matter on which the battle amongst its components is based. On one hand, those members in favor of the utter need to re-launch and strengthen the role of the party and of the project of 
communist refoundation without rejecting the historical need for a strategic unity amongst all the forces of the left wing. On the other hand, those members that have instead considered any Refoundation Communist Party "salvaging" speech as indissoluble from a pact with the constituent and with the so called collective left wing. Amongst the principal critics of the "overcoming" perspective of the PRC are the supporters of the first motion in favor of a new political entity and against the "appeal for only one party already presented and ready to be publicized after the elections" in the event that the electoral result would have been less catastrophic. On the contrary, the starting point should be "the "refoundation" of the Refoundation Communist Party as a social party", knowing that the problem isn't just that of rebuilding the party but also of "rebuilding the distressed common sense, the logic, the coherence and the solidarity". In order to meet this result it is necessary to reclaim the need, "for today and tomorrow, of a mass communist party that hopes for a refoundation of the communist thought and practice" and this is because the communists are convinced that in the time of crisis of the meta-narrations of the nineteenth century "it is healthy and normal that a party would have its identity" that needs to be "strengthened and not humiliated". The issue "isn't to overcome the party as much as the need to re-evaluate its internal democracy along with the tools that may allow a true" communist refoundation and consequently of the left wing. Unity "rises from the bottom up". The hypothesis of a constituent of the left wing or of a communist party "find reciprocal advantage from an unbalanced symmetry however obvious: to lock communism in a testimonial ghetto outside history". It is necessary to commit to "the refoundation communist project while working, at the same time, to the construction of a left wing unity starting from the society, from the battles and from the movements, while being opposed to the right wing parties". Thus, "an open communist refoundation process able to contribute to the growth of an opposing left wing, that is strong, flourishing, and plural", because "in a "fluid" society a left wing without a critical understanding of itself it is simply the negation of what it is". In the wake of this line of thought, the third forth and fifth document supporters connect, even though they share different approaches. In specific, the patrons of the third motion advocate to the reconstruction of a mass communist party that goes against those who have worked for years just for the "severance package" of history and of the communist political culture against those comrades who "vis-à-vis the proposal of engaging the refoundation in building a great communist party turn away from it, in the best case scenario, and even arrive to the point of not considering this proposal an alternative to the original inspiration" of the party, this "in the name of a "nuovism" erroneously mistaken for "innovation"“ that brought the entire left wing to a colossal defeat "while the mission of the refoundation is to rebuild the communist party". In order to reach this goal, however, "it is necessary to start from an explicit self-criticism of the communist forces ... that will call into question the governist inclinations along with the preeminence given to the tactical maneuver and the”. If, in fact, the PRC “doesn't want to continue being absent minded when it comes to cultural tendency, it needs to organize itself in a strong communist organization aimed to the anti-capitalism war, even on worldwide basis". So, "the chickens of theorizing (and practicing) a "volatile party" " have come home to roost, along with their fraudulent inability to detach from the "élite" to which the traditional "communist diversity" is juxtaposed. It is also worth pointing out that there is a strong "need to recuperate the leading role of the party base, of its democratic life and of the creation of leadership groups able to perform collective work while directing responsibly the body of the Party" against the seeds of leaderism.

Also, the supporters of the forth document state the need for a party that gives up its governist and institutional gown to fully live the role of "the battling and opposition party that would build itself leveraging the social conflict". To save the PRC "it is necessary to break up with any hypothesis of collaboration, on both the national and international level, and to break up with those parties that still have ties with" the ruling class. "The current priority isn't to simply govern, but to organize and politically prepare the party for the opposition, systematically intervene on movements behalf and about the social conflict", because "the true "social benefit" of a communist party is measured by its ability to organize the working class in the battle for communism". Additionally, the supporters of the fifth document ask for a discontinuity of the cultural acquisitions claim of the PRC that have allowed, through the years, to be on the same wavelength of the movements in different social sectors of the battle. In spite of this, burocratism and leaderism errors are still noted. So, it is necessary to oppose them with a "self-reform coming from the bottom up of the party, along with its decentralization, socialization and democratization". It is therefore necessary to think about a possible "relinquishment of the sovereignty, both on the national and territorial levels", in favor of a "not centralized glocal party able to get rid of the distance between political and social, supporting the needs and the questions of the territories while promoting the local opposition to the neo-liberal politics". A party founded on "mutualism, on collective democracy and on an open mind towards a community perspective from the bottom up", in the end, a new social party "that would finally presents revolutionary features". On the contrary, the setting of the second motion "is addressed to both the party and to the many disillusioned comrades filled with doubts" who live their political scene outside the boundaries of the party-form. This presumes "a true open mind to the reasons of the other", since the social action of the party "is often perceives as devoted to the marginal areas or 
to the themes of the élite". Therefore, "a leap is needed in order to come out of some refined and self-referring logics". To set an underlying goal: change, or in other words, to change ourselves to transform the society" through the construction of "a shared Italian left wing house" as a true "constituent of the left wing that without scattering the richness of the past" would accept the challenge of "recomposing a political and social subjectivity of the alternative left wing".

\subsection{Economy and employment}

All the motions give room to the analysis of the productive processes and to role of the employment within the definition of a communist left wing political culture. In specific, the first, third and forth document focus on the need to restart from the centrality of the conflict asset versus employment. Additionally, in the second document and in the fifth document, in a less obvious way, the more problematic approach is presented denying the existence of a sole contradiction that needs to be focused upon within the field of the transformations and which took place due to the capitalist globalization. The supporters of the first document, instead, speak of the need to identify a "concrete political option that forces to give more attention to the social and class conflict". They also emphasize those "differences in cultural politics that diversify those who persevere in thinking in terms of class conflicts and revolutionary commitment in order to overcome capitalism, and those who organize the themes of the conflict, instead". This is referred in specific to the second motion where "the connection between the "social condition" and the "political enrollment" is declared lost, deeming outdated a conflict to build hegemony on class basis" precisely when "a similar kind of battle would be the leading criterion in the concept of opposition" of the social and government right wings. Hence, it is necessary to find the courage to "self-define and self-motivate within the public field" in order to build "an opposition that would reconnect the conflict with the politics and that would be able to build social ties and the hope for a collective behavior". Following this direction, it is essential to prepare for an "out of the ordinary mobilization against the hypothesis of modifying a contractual model that decreases the function of the collective national contract and resumes the battle for an increase of wages". Then, it is pivotal "to defend society from privatization and from a cut in services and from a campaign against public workers". Similarly, the supporters of the third motion state the need to put into play "a strong entity that would take upon itself the class conflict as the fulcrum of its activity and that would adopt anti-capitalism as its political scene" against that single neo-liberal thought that "in the name of productivity and anti-capitalism aims to the division of the working class". To this end, it is essential that all of us make the necessary efforts, also on an analytical level, "to describe the dynamics that characterize the capitalistic system and a "renewed" labor class more exploited and less conscious, not able to understand the existing contradictions" and how to fight them. Only this way, one will be able to determine "the action unity amongst the conflicting union entities and the conflicting classes" which represent "the most effective answer to the political and social right wings offensive". It is not enough to "return in front of the factories gates", however it is necessary "to go into the factories and work in them, because "it is precisely within the factories that the party has to claim its role". "The employment needs to be lived and cannot be imagined". Furthermore, the supporters of the forth motion (that not randomly define itself as the labor motion) view "the class independence as an essential trait of the communist politics" being able to intervene on the factory processes and to become part of the union contradictions because "if we are not able to connect the union and to the class politics how will we be able to stop the master's marching offensive?”. Therefore, it is needed a class vision that will act as a magnifying glass through which we will analyze apparently different the class processes as for example the migration phenomenon. In fact, "the history of the people immigration processes is also the history of the worldwide social conflict: battles that aim to a better quality of life and are against the power". Hence, the battle needs to be put forward "starting from the opposition to the counter reform of the national employment contract" being part "of the social conflict aided by the militants inside and outside the factories". Beyond any easy statement on the "centrality of the conflict asset versus employment", "it is time to start up a metamorphosis that will allow the party to firmly settle within the working class arena”. Moreover, the supporters of the fifth document don't allow room to the issue of employment and the class conflict even if they do not neglect the need to analyze and face the growing "precariousness" along with the phenomena of "slavery within the field of waged work" and within a "shattered" society where the "ethicized working force" is exploited. Thus, it is pivotal to bring forth a permanent mobilization for "the job and workplace safety. A safety that is brought to life by solidarity and integration" against the master's logic that entails "a cheap production as the Chinese market is able to offer and an expensive sale as in the German market, where poor people are forced to produce while rich people may consume". Additionally, the supporters of the second document do not deny the importance of employment and class conflict however vis-à-vis the complexity of the context state that "we should stop the litany regarding factories, territories and to demonstrate in the streets" because, at least, in the Western world, one cannot consider employment just as "subordinate or at the most "precarious". As an alternative, "we may and we have to - moderately - begin the plural grammatical declension of "class", including decisive factors like self-employment and SME employment as they indicate, in this day and age, 
from a structural and Marxist point of view, those workplaces that are exploited by the capitalistic system”. Hence, it is unavoidable to have to come to terms with "the age of employment after class". So that it will be possible to also oppose to the "choice made by the European Union to increase working hours to 65 per week" clearly uncovering "the global capitalistic socio-political directive: more work, reduced wages".

\subsection{Social movements}

As we witnessed from the V Congress onward, the PRC started a realigning process of its goals that resulted in a detachment from the typical communist tradition which envisioned the party as the leading edge entity of the deprived masses, and in the wake of the mobilization against the capitalist globalization the party theorized and practiced the cohesion of its internal movements; less than a decade after, the privileged relationship with the movements seemed, by this time, acquired as a pivotal element on which to be elaborate the Refoundation Communist Party parameters. The supporters of the first motion stated the need to "re-launch the movement for peace and against the increasing military expenditure" because to resume with a firm belief "the road of the movement against globalization", the only possible way is "to build a left wing that offers and alternative to the great coalition that governs the country". Thus, it is necessary to work at it in order "to create a political entity for the union and labor movements, for the women, ecological and pacifist". In short, it is essential to work "to build a cohesive left wing" however "beginning from society, conflicts and movements". Additionally, the supporters of the second motion on the same wave length, state that the political suggestion "regarding the reconstruction of an alternative political and social left wing" that needs to be connected to the experience of "the movements with which we need to put up for discussion" the blue collar worker of the party "in an open minded way that is participating and offers equal dignity". Hence, the new left wing that needs to be rebuilt "will have to feed on the movements and on the "typical" territorial conflicts (i.e. social, ecological, and about public rights)" and to do so it will have to work at "resigning from the party arrogance directing itself towards a search for a relationship with the movements based upon equal dignity". Moreover, the supporters of the third document believe that the "issue needs to be analyzed in a more concrete environment" i.e. putting into practice "the relationship with the movements" and not simply limiting itself to preach a futile "political activism that stands as an ideological principle". Without a doubt the "opposition" is destined to "engage in a new season of thematic movements" but the party "cannot forgo a general synthesis of the different thematic movements". The party has "to promote battle committees and doesn't have to limit itself to just be on the side of the conspicuous movements however it needs to fuel them". Furthermore, the position of the supporters of the forth document, deem that the party should salvage the relationship with the movements and with the different territorial committees, since the governmental experience has had the only possible outcome: "to tone down the conflicts in exchange for the survival of the "friendly" government, with the result that during that time the movement has experiences quite a lot of stress". Vis-à-vis this difficult phase, it is "necessary to promote a true consultation amongst all those who think that this movement is a concrete opposing reality" while building a collective program along with some conditions for "a systematic intervention from the bottom up, that is also detailed while building self-organized movements, committees, work force coordination in order to collect the necessary forces needed for this decisive battle". Also, the supporters of the fifth document focus on the issue of the relationship with the movements stating that it is essential to salvage this organic relationship with all the movements "without any hegemonic demands or hocus pocus but simply challenging oneself in the toil of being a real movement and not just emphatically speak about it". On one hand, it is not copasetic to demand the elaboration of a "salvaging recipe" to then go and "preach the holy word of Christ to the masses and to the movements". On the other hand, nowadays, it is necessary to practice the refoundation that "doesn't merely represent the breaking off of the hierarchy of the political parties, movements and associations, rather it is the acquisition of an alternative political scene that has the society as its center" as part of a communist culture and of a truly renewed left wing.

\section{Conclusions}

On the basis of the just carried out analysis, the image of a party divided and in trouble surfaces mainly after the electoral defeat which acted as a detonator for the internal conflicts. Generally, every organization is implicated in a large number of relations with the outer environment. A political party may try to overpower its environment or better try to adapt to it, narrowing its range to just "being on the market", as for example trying to survive within the free gaps left by the other larger political parties, however, this would go against the historical role of the communists. In fact, it is generally recognized that no communist party has ever limited itself to just translating the social petitions of the subordinate classes in a political way, merely following the principle of a sociological representation, rather it has aimed to control its social base while working on it (Gruppi 1980) also, within the picture of a complex political arena i.e. that of the political expansion and of the mass consensus, it still has been something to aspire to for the activists and the PRC leading group. Moreover, the dichotomy: adaptation/control may result misleading. In the first place because the party attitude compared to its outer surroundings is heavily 
dependent on the environmental conditions. Secondly, when we speak of outer environment doesn't mean a cohesive social and political entity but rather a collection of arenas within which the party operates and within which the party may develop diversified strategies. Through the content analysis, we have denoted that PRC militants are still carriers of a "strong thought" that may lead the entire organization out of sandbank where the political junction has relegated it. Differences and analogies begin to stand out however, generally, on issues that need to be resolved, such as employment, globalization, democracy and the dialectical relationship with the social movements and the territorial conflict experiences, which displayed margins for a cooperative work, in specific, on the issue of the democratic management of the party, where, in fact, wide margins of convergence are present, as shown by the recent research made about PRC members, which clearly revealed the perception of a democracy deficit in the decisional internal processes. In fact, $78 \%$ of the interviewees declared to be a little satisfied of the influence that they thought to have within the party, while $29 \%$ believed that there was a little democracy within the party, and $42 \%$ agreed with the statement that the parties leading group didn't care about the opinions of the members (Mulé 2005, 20-22). Actually, a dominant coalition isn't always absolutely cohesive or divided as it isn't always completely stable or unstable, as a matter of fact, many are the factors that play a role when defining hybrid forms. In the case of a stable and cohesive coalition, one may speak of a monocracy, depending on the cases, when a central leadership is really strong, while an oligarchy is intended as the way to manage the power in which a coalition has an out of proportion influence on the collective decisions of the group (Schonfeld 1980, 858). Instead, when analyzing coalitions as divided or unstable one may speak of polyarchy characterized by the existence of two or more groups relatively organized, none of which, is individually in the condition to impose a hegemonic control on the organization (Dahl 1971). Therefore, we may say that the Refoundation Communist Party has lived in a monocracy condition, if only in the last decade or at least it has lived in an oligarchy where the apparently cohesive and stable coalition was in fact held together by the consolidating figure of a charismatic leader. Hence, the oligarchic condition was then strengthen by the choice made at the VI Congress, of a majority management of the party, thus keeping out all the minority components from the decisional processes. In fact, the outcome of the VII Congress reveals the image of a precarious majority created by an agreement amongst the four minority motions ( 1 , $3,4,5)$ which reflect the polyarchic situation where the new coalition will supposedly present the traits of its division and instability, following the above mentioned typology. In fact this outcome is never predictable. The legitimacy (and consequent stability) of a dominant coalition in reality connected to its ability to translate the official goals of the organization into a political line. Although, it is as important to be able to offer a credible path to follow while pursuing such goals.

This way, a political line is "the tool or the collection of tools whose explanation is essential in order to give credibility to its "cause" and to thus fuel it function of a symbolic "center" of identification" (Panebianco 1982, 92), besides being the base of compromise on which the stability of a coalition is defined. In accordance with this thought, from the VII Congress onward a political line has been translated into a final agenda signed by the representatives of the first, third, forth and fifth motion. We already noticed, in the content analysis, that the supporters of the four documents were on the same wavelength about the need to re-launch the party avoiding any possible leadership degeneration. This theme that since the beginning represented the pivotal issue of the VII Congress is clearly stated in the final document where "the proposal of the left wing constituent is rejected along with any hypothesis of overcoming it or even the hypothesis to merge the PRC in a different political scheme". Clearly, the match about the left wing unity doesn't end here, and similarly the issue stands as an open problematic field for "research and new testing grounds". Likewise, a congruous analogy has been noted regarding the autonomous and alternative role of the PRC when compared to the Democratic Party and about the need to start up a lengthy phase of social opposition, two of the well stated concepts in the final agenda where it is expressed that given the existent power relationships "the Italian Congress will consider the phase characterized by the organic collaboration with the PD, closed and overcome" and that the "re-launching of the PRC has to be characterized in the first place by a left wing turnaround" distinguished by the recovery of the idea that "the opposition isn't merely a location within the political picture, however it is depicted as a reconstruction phase, a rooting phase, as a social relations phase and as a phase of cultural and political battle" that would start from the issue of employment. Along these lines, it is offered "to put into play a strong initiative in defense of: the lower classes quality of life and employment conditions, in defense of the issue of wages and retirement checks, in defense of the solution to the issue of the battle to precariousness and to the initiative against unemployment". In conclusion, the PRC "resuming the path that began in Genoa, confirms its cohesiveness to the worldwide movements against the capitalist globalization and, within this picture, it confirms its willingness to intensify the collaboration and the relationships with other progressive communist parties, along with all the revolutionary movements and the Latino American experiences that set against the war and neo-liberalist politics". In the end, there are the conditions so that the dominant coalition of the VII Congress may show the cohesive and necessary traits to overcome this critical phase. 


\section{References}

Andretta M., D. Della Porta, L. Mosca, H. Reiter. (2002). Global, No Global, New Global, Roma: Laterza.

Belloni F.P., D.C. Beller (1978, eds.). Faction Politics: Political Parties in Comparative Perspective, Santa Barbara: ABC Clio.

Bertolino S. (2004). Rifondazione comunista. Storia e organizzazione, Bologna: Il Mulino.

Blau P. (1964). Exchange and Power in Social Life, New York: Wiley.

Bolardini P., A. Di Virgilio. (2005). Partito dei comunisti italiani. Ritratto di un partito che no avrebbe dovuto esserci, paper presented in occasion of the seminar organized by the Department of Organization and Political System of the University of Bologna, October 11.

Dahl R. (1971). Polyarchy. Participation and Opposition, New Haven and London: Yale University Press.

de Nardis F. (2003). Cittadini globali. Origini e identità dei nuovi movimenti, Roma: Carocci.

de Nardis F. (2004a). I new global al forum sociale europeo. Politica, democrazia, partecipazione negli atteggiamenti dei giovani antiglobalisti, Quaderni di Scienza Politica, 1, 85-106.

de Nardis F. (2004b). Il movimento antiglobalista. Genealogia e portata della società civile globale, Sociologia e politiche sociali, 1, 11-62. http://www.francoangeli.it/Riviste/Scheda_Rivista.aspx?idArticolo=25242\&lingua=it

de Nardis F. (2005). Sinistra in movimento. La rifondazione comunista dalla resistenza globale al governo di alternativa, Quaderni di Scienza Politica, 3, 409-455.

de Nardis F., F. Della Ratta. (2006). Rifondazione Comunista at its 6th National Conference: a strategy of textual and semantic analysis, JADT 2006, in Actes des 8^es Jornées Internationales d’Analyse Statistique des Données Textuelles, Presse Universitaires de $\quad$ Franche-Comté, $\quad$ pp. 341-353. http://lexicometrica.univ-paris3.fr/jadt/jadt2006/PDF/030.pdf

de Nardis F. (2009). La rifondazione comunista. Asimmetrie di potere e strategie politiche di un partito in movimento, Milan: FrancoAngeli.

della Porta D. (2001). I partiti politici, Bologna: Il Mulino.

della Porta D. (2007). Movimenti sociali e partiti politici. Un gioco a somma zero?, Rassegna Italiana di Sociologia, 3, 503-532. doi:10.1423/25491, http://dx.doi.org/10.1423/25491

della Porta D., M. Andretta, L. Mosca. (2003). Movimenti sociali e sfide globali: politica, antipolitica e nuova politica dopo l'11 settembre, Rassegna Italiana di Sociologia, 44, 43-76. doi: 10.1423/8566, http://dx.doi.org/10.1423/8566

della Porta D., M. Andretta, L. Mosca, H. Reiter. (2006). A Movement of Movements. Transnational Activists and Protest Networks, Minneapolis: University of Minnesota Press.

della Porta D., M. Diani. (2006). Social Movements. An Introduction, Oxford: Blackwell.della Ratta F., F. de Nardis. (2006b). La Rifondazione Comunista alla prova del VI Congresso: una strategia di analisi testuale e semantica, Quaderni di Sociologia, 42, 195-210.

Dormagen J-Y. (2004). I comunisti. Dal Pci alla nascita di Rifondazione comunista. Una semiologia politica, Roma: Koiné.

Gruppi L. (1980). La teoria del partito rivoluzionario, Roma: Editori Riuniti.

Katz R., P. Mair. (1992, eds.). How Parties Organize: Change and Adaptation in Party Organizations in Western Democracies 1960-1990, London: Sage.

Kitschelt H.P. (2003). Landscapes of Political Interest Intermediation: Social Movements, Interest Groups, and Parties in the Early Twenty-First Century, in P. Ibarra (eds.). Social Movements and Democracy, Houdsmill, Basingstoke: Palgrave-Mcmillan, 81-104.

Mair P. (1992). La trasformazione del partito di massa in Europa, in M. Calise (ed.). Come cambiano i partiti, Bologna: Il Mulino.

Michels R. (1998). Political Parties: A Sociological Studies of the Oligarchical Tendenciesof Modern Democracy, New York, The Free Press. 
Mulé R. (2005). Mutamenti nella democrazia infrapartitica: dalla teoria ai dati e ritorno. Analisi di un sondaggio agli iscritti $D s$ e Rc, paper presented in occasion of the seminar organized by the Department of Organization and Political System of the University of Bologna, October 11.

Norris P. (2002). Democratic Phoenix. Reinventing Political Activism, New York, Cambridge University Press. doi:10.1017/CBO9780511610073, http://dx.doi.org/10.1017/CBO9780511610073

Panebianco A. (1982). Modelli di partito, Bologna, Il Mulino.

Rose R. (1976). The Problem of Party Government, Harmondsworth, Penguin Books.

Rucht D. (1990). The Strategies and Action Repertoire of New Movements, in R.J. Dalton, M. Kuechler (a cura di). Challenging the Political Order. New Social Movements in Western Democracies, Cambridge: Polity Press, 156-175.

Schlesinger J.A. (1966). Ambition and Politics, Chicago: Rand McNally.

Schonfeld W.R. (1980). La Stabilité des Dirigeant des Partis Politiques: La Théorie de l'Oligarchie de Robert Michels, Revue Française de Science Politique, XXX, 858.

Tucker R. (1970). The Theory of Charismatic Leadership, in D. Rustow (a cura di). Philosophers and Kings: Studies in Leadership, New York: Braziler.

\section{Notes}

Note 1. On one hand, collective incentives refer to benefits or promises of future benefits that the organization should evenly give to all the participants. On the other hand, we identify selective benefits as those benefits that are unevenly given. Collective incentives may be classified as identity incentives (when one participates because identifies himself/herself with the organization), or as solidarity incentives (when one participates in solidarity with the other participants), and ideological incentives (when one participates because he/she identifies himself/herself with the organization "cause"). The selective incentives instead have to do with material, power or status expectations. To know more on the incentives theory we suggest Schelsinger (1966); Panebianco A. (1982).

Note 2. The IS index takes into account the absorption degree of a segment compared to the words that compose it, for example: if the segment $<$ to be communists - essere comunisti $>$ is present 10 times in the text and the terms $<$ to be $>$ and $<$ communists $>$ are repeated respectively 8 and 10 times, one may say that the segment in question absorbs the $83,3 \%$ of the frequencies of the word $<$ to be $>$ and $100 \%$ those of the word $<$ communists $>$. It is possible to say then that this segment has a very high specificity since the two terms that compose it, are almost never used outside it. Thus it is useless to consider these two graphical forms in a separate way, because in the text it is almost exclusively mentioned $<$ to be communists -essere comunisti $>$. Hence, a segment will be as relevant as it is stronger the degree of absorption of the word that compose it.

Note 3. It is then clear, the claiming appeal of the, at the time, president of the House of Representatives and the left wing "arcobaleno" candidate to the charge of Prime Minister, Mr. Fausto Bertinotti, that in an interview stated that the new political content of the left wing: the communism, which he strongly supported, would have become an internal cultural trend.

Note 4. The textual analysis computer based program TALTAC will be also used to compare the analyzed text with the lexicon frequency. Clearly, the higher the value of the deviation the more the graphical form may be considered peculiar to the text at hand.

Note 5. For this last operation we will use Lexico3, a specific statistical program used in lexicon-textual analysis. 